University of Warwick institutional repository: http://go.warwick.ac.uk/wrap This paper is made available online in accordance with publisher policies. Please scroll down to view the document itself. Please refer to the repository record for this item and our policy information available from the repository home page for further information.

To see the final version of this paper please visit the publisher's website. Access to the published version may require a subscription.

\author{
Author(s): Steve Fuller \\ Article Title: American ambivalence towards academic freedom \\ Year of publication: 2006 \\ Link to published version: \\ http://dx.doi.org/10.1017/S0140525X06009228 \\ Publisher statement: None
}


Behavioral and Brain Sciences (2006), 29(6):577-578 Cambridge University Press Copyright (C) 2007 Cambridge University Press doi:10.1017/S0140525X06009228

Open Peer Commentary

\title{
American ambivalence toward academic freedom
}

\author{
Steve Fuller ${ }^{\text {a1 }}$ \\ ${ }^{\text {a1 }}$ Department of Sociology, University of Warwick, Coventry CV4 7AL, United \\ Kingdom. s.w.fuller@warwick.ac.uk http://www.warwick.ac.uk/ sysdt/Index.html
}

\section{Abstract}

Why are U.S. academics, even after tenure and promotion, so timid in their exercise of academic freedom? Part of the problem is institutional academics are subject to a long probationary period under tight collegial control - but part of the problem is ideological. A hybrid of seventeenthcentury British and nineteenth-century German ideals, U.S. academia - and the nation more generally - remains ambivalent toward the value of academic freedom, ultimately inhibiting an unequivocal endorsement.

Is tenure justified? An experimental study of faculty beliefs about tenure, promotion, and academic freedom Ceci Stephen J. Williams Wendy M. Mueller-Johnson Katrin Department of Human Development, Cornell University, Ithaca, NY 14853.sjc9@cornell.edu http://www.people.cornell.edu/pages/sjc9/; Department of Human Development, Cornell University, Ithaca, NY 14853.wmw5@cornell.edu http://www.human.cornell.edu/che/bio.cfm?netid=wmw5; Faculty of Law, University of Cambridge, Cambridge CB3 9DT, United Kingdom. kum20@cam.ac.uk

What is perhaps most surprising about Ceci et al.'s study of the relationship between academic rank and attitudes toward "academic freedom" is not its findings but the apparently primitive state of empirical research examining the matter. Moreover, contrary to the authors' suggestion, the United States, although perhaps the nation most ideologically committed to tenure as a vehicle for promoting academic freedom, does not have an especially coherent normative justification for the practice. As in so many other matters, the United States filters aspects of the British and German experience through its own distinctive history. The result is a lively mélange of competing notions that render the concept of academic freedom "essentially contested."

Ceci et al.'s findings themselves are predictable: Tenured full professors are more comfortable challenging the words and deeds of their colleagues than 
are academics who have yet to complete either the tenure or the promotion process, with all ranks turning out to be more timidly disposed than any of them had imagined. Surprisingly, Ceci et al. do not draw the most obvious conclusion to explain this result; namely, that in American universities, tenure and promotion are subject to relatively strong collegial oversight for a relatively long period. The pressure to conform to local norms is thus unusually strong, especially in the run-up to a tenure decision, and it has lasting effects on the candidates. (This policy also affects the examination of doctoral dissertations, the fate of which is almost always determined inhouse.)

From a European standpoint, the United States is striking in the weight accorded to a candidate's local public relations. The good will of tenured and promoted members of a candidate's department is essential for success, as higher levels of academic administration tend to respect the judgments issued at lower levels, unless circumstances clearly indicate otherwise. The hiring of even full professors in the United States is treated as primarily a departmental, rather than a university, appointment. Issues captured by the phrase "team player" can easily eclipse whatever merits a candidate brings as an individual. Moreover, a consequence of the relative autonomy enjoyed by U.S. academic departments is that their members are more preoccupied with boundary maintenance. Thus, every prospective tenure candidate raises the spectre of opportunity costs; namely, the other possible candidates one might hire - and who might be a better fit - if this one is denied tenure.

The solution would seem to be simple: Refer tenure and promotion decisions to a higher level of the university, and over a shorter period of time, to remove local prejudice and inhibit the formation of conformist attitudes. For example, the probationary period for regular academic staff in the United Kingdom has been traditionally only 3 years, not 6 or 7 . The several levels of promotion are still based on inter-departmental competitions, where the frame of reference is the overall contribution to the university and the candidate's discipline, not specifically the well-being of his or her department. To be sure, the United Kingdom has drifted over the past two decades toward a more U.S.-style system, but this has happened for reasons unrelated to academic freedom.

On the one hand, longer probationary periods allow more discretion for administrators to reconstitute academic units to fit changing market conditions. On the other hand, a stress on departmental cohesion is more likely to generate a distinctive "research culture," which is a key indicator in national academic performance measures.

The large question that looms behind Ceci et al.'s findings is whether academics are themselves the best guarantors of academic freedom. Given the self-organizing origins of the American Association of University Professors, the answer may appear to be obviously yes. However, Germany under the Second Reich provides an alternative precedent. Academic freedom in this context was not simply a specialised version of free speech but a guild privilege of a certain profession not enjoyed by society at large. Corresponding to such privileges were obligations, not least of which was to publicize one's research in the classroom and the wider society. Moreover, academics could 
legally criticize state policy by invoking the spirit of the "nation" that may have temporarily eluded the politicians. But could academics be trusted to administer their own delicate position? The answer was no, as academics were as self-serving as anyone else. Here the higher-education minister, Friedrich Althoff, did all he could to control the hiring and promotion of professors, typically by preventing the formation of local academic dynasties through nationwide competitions. The "Althoff system," although irritating the likes of Max Weber, is largely credited with having propelled Germany to scientific preeminence in the years leading up to the First World War (Spinner 1993). The mere reinforcement of local norms was insufficient for academic advancement: Ambitious academics had to strike out in innovative ways that appeared to promote the national interest.

America's constitutionally devolved educational authority renders a homegrown version of Althoff highly unlikely, except perhaps at the level of state university systems. However, Althoff indirectly throws light on a fundamental ambivalence about the U.S. commitment to academic freedom. As Ceci et al. rightly observe, attacks on academic freedom from both the political right and left have often centred on the anticipated consequences of taking seriously what academics have said. In the German context, this would be a problem only if a professor threatened national security or, more immediately, abrogated students' freedom to learn. (David Horowitz's campaign to have U.S. universities adopt an "academic bill of rights" taps into this latter sentiment.) However, the more vague but pervasive American challenges to academic freedom hark back to the campus-based setting of the original colleges (modelled on Oxbridge) that anchor so many normative intuitions about university life in the United States, regardless of institutional foundation (Fuller 2002, pp. 220-25). These intuitions, epitomized in the legal expression "in loco parentis," are most clearly manifested in what is often praised as the pronounced pastoral side of American university life. But it may also be that this residual idea of the university as the extended family (i.e., "alma mater") may also encourage an overprotective self-censorship that ultimately undermines an unequivocal defence or exercise of academic freedom.

Reference:

Fuller, S. (2002) Knowledge management foundations. Butterworth-Heinemann.

Spinner, H. (1993) Althoff and the changing constitution of science. Journal of Economic Studies 20(4/5): 134-66. 